\title{
Current practices in the clinical and psychometric assessment of internet gaming disorder in the era of the DSM-5: A mini review of existing assessment tools
}

\author{
Halley M. Pontes* \\ Nottingham Trent University, International Gaming Research Unit, Psychology Division, Nottingham, United Kingdom
}

\section{Introduction}

As of May 2013, the American Psychiatric Association (APA) published the fifth edition of the Diagnostic and Statistical Manual of Mental Disorders (DSM-5) and introduced Internet Gaming Disorder (IGD) in the Section III (Emerging Measures and Models) of the DSM-5 [1] as a tentative disorder warranting further research before being included in future editions of the DSM and fully recognized as an independent clinical disorder [1,2]. Moreover, IGD is defined in the DSM-5 as a 'persistent and recurrent use of the Internet to engage in games, often with other players, leading to clinically significant impairment or distress' (p. 795), as indicated by five (or more) of the following nine criteria: (i) preoccupation with games, (ii) withdrawal symptoms when gaming is taken away, (iii) tolerance, (iv) unsuccessful attempts to control the participation in games, (v) loss of interests in previous hobbies and entertainment as a result of, and with the exception of, games, (vi) continued excessive use of games despite knowledge of psychosocial problems, (vii) deception of family members, therapists, or other regarding the amount of gaming, (viii) use of games to escape or relieve a negative mood state, (ix) jeopardy or loss of a significant relationship, job, or education or career opportunity because of participation in games [1].

Previous studies [3-6] have shown how assessment tools and conceptual frameworks defining addictive gaming behavior prior the DSM-5 were inconsistent and how they hindered the field of the assessment of IGD. Therefore, several authors $[3,5,7,8]$ have recently made a call to standardize and unify the assessment of IGD given that the field now has an objective set of criteria and preliminary conceptual framework defining the phenomenon that was put forth by an official medical body (i.e., APA). In light of this, a few psychometric and assessment tools (see Table 1) have been developed since then. To the best of the author's knowledge, the field of IGD has now a set of seven clinical and psychometric instruments based on the updated framework set by the APA to assess the phenomenon of addictive gaming behavior.

The recent proliferation of IGD assessment tools denote, in the one hand, that consensus on how to assess the disorder remains elusive.
This is particularly noticeable by the development and publication of assessment tools that completely overlap with existing ones [e.g., 9], adding further confusion to the field. Notwithstanding this, Table 1 makes it clear that researchers are indeed attempting to move the area forward and further beyond its 'unofficial' status since most of the newly developed assessment tools have consistently relied on the nine IGD criteria as the rationale for devising such instruments [9-12]. On the other hand, however, such studies are bound to provide potentially meaningful evidence in the near future either in favor or against the way in which IGD is defined and conceptualized by the APA, allowing new evidence-based criteria and models to emerge and fill in potential gaps [13-15].

Although the field of IGD is still in its early infancy, based on the latest progresses the field have witnessed, the following recommendations are made to help move forward and improve future research on IGD: (i) more scientific scrutiny is needed on each IGD criterion in terms of the impact and weight they may carry towards the final diagnosis, (ii) existing assessment tools would greatly benefit from further clinical studies utilizing actual clinically diagnosed samples so more concrete information on the validity and diagnostic properties (e.g., sensitivity, specificity, negative and positive predictive values) of these tools could be gathered, (iii) acquiring further longitudinal evidence on IGD is paramount for understanding the potential etiological mechanisms and clinical course of the disorder, such studies might provide useful evidence supporting the recognition of IGD as an official disorder, and (iv) large-scale nation-wide studies using probability samples and the already available new standardized psychometric tools are needed in order to estimate robust prevalence rates of IGD that can then be contrasted with prevalence rates found elsewhere, and that can be reliably be used by governmental bodies and other stakeholders in the process of policy making and development of adequate treatment protocols needed for this disorder [16,17].

Correspondence to: Halley M. Pontes, Nottingham Trent University, International Gaming Research Unit, Psychology Division, Nottingham, United Kingdom, Tel: +265.999.289.570; E-mail: halleypontes@hotmail.com

Received: March 25, 2016; Accepted: April 26, 2016; Published: April 29, 2016 
Pontes HM (2016) Current practices in the clinical and psychometric assessment of internet gaming disorder in the era of the DSM-5: A mini review of existing assessment tools

Table 1. Current available psychometric and clinical assessment tools to evaluate Internet Gaming Disorder (IGD) according to the American Psychiatric Association's conceptual framework.

\begin{tabular}{|c|c|c|c|c|c|c|}
\hline Instrument & Number of items & Type of scale & Time-scale & Addiction criteria & Clinical validation & $\begin{array}{l}\text { Cross-cultural } \\
\text { validation }\end{array}$ \\
\hline $\begin{array}{l}\text { The Internet Gaming Disorder Test (IGD-20 } \\
\text { Test) [10] }\end{array}$ & 20 & Continuous & 12-month & Scoring $\geq 71$ points & No & Spain [11] \\
\hline $\begin{array}{l}\text { Internet Gaming Disorder Scale-Short-Form } \\
\text { (IGDS9-SF)[12] }\end{array}$ & 9 & Continuous & 12-month & Endorsing $\geq 5$ criteria $^{\mathrm{a}}$ & No & $\begin{array}{c}\text { Portugal [13] } \\
\text { and Slovenia [14] }\end{array}$ \\
\hline $\begin{array}{l}\text { The Internet Gaming Disorder Scale (IGDS) } \\
{[15]^{\mathrm{b}}}\end{array}$ & 27 & $\begin{array}{l}\text { Dichotomous and } \\
\text { Continuous }\end{array}$ & 12-month & NR & No & No \\
\hline $\begin{array}{l}\text { The Internet Gaming Disorder Scale (Short } \\
\text { Scales) }[15]^{\mathrm{b}}\end{array}$ & 9 & $\begin{array}{l}\text { Dichotomous and } \\
\text { Continuous }\end{array}$ & 12-month & Endorsing $\geq 5$ criteria & No & No \\
\hline $\begin{array}{l}\text { The Ten-Item Internet Gaming Disorder Test } \\
\text { (IGDT-10)[16] }\end{array}$ & 10 & Ordinal & 12-month & Endorsing $\geq 5$ criteria $^{\mathrm{c}}$ & No & No \\
\hline $\begin{array}{l}\text { Clinical Assessment } \\
\text { Tool (C-VAT 2.0) [17] }\end{array}$ & 14 & Dichotomous $^{\mathrm{e}}$ & 12-month & Endorsing $\geq 5$ criteria $^{\mathrm{f}}$ & Yes & No \\
\hline $\begin{array}{l}\text { The Personal Internet Gaming Disorder } \\
\text { Evaluation-9 (PIE-9)[9] }\end{array}$ & 9 & Continuous & 12-month & Endorsing $\geq 5$ criteria $^{\mathrm{g}}$ & No & No \\
\hline
\end{tabular}

${ }^{\text {aA }} \mathrm{A}$ criterion is endorsed when a participant provides the maximum response possible in that item (i.e., 'Very often').

${ }^{\mathrm{b}}$ Both the IGDS and its shorter version were developed in the same study.

"Endorsement of each criterion is assessed upon conversion of the original three-point response scale (i.e., "never", "sometimes", and "often") each item into yes/no

${ }^{\mathrm{d}}$ The C-VAT 2.0 is a clinical assessment tool, therefore its administration is made by a trained clinician

${ }^{\mathrm{e}}$ Only the nine items referring to the nine IGD criteria

In terms of diagnosis, only the nine items referring to the nine IGD criteria are considered in the diagnostic process

gA criterion is endorsed when a participant respond with either 'Very often' or 'Often' to an item.

\section{References}

1. American Psychiatric Association, Diagnostic and Statistical Manual of Mental Disorders (5th ed.). 201, Arlington, VA: Author.

2. O’Brien JE, Li W, Snyder SM, Howard MO1 (2016) Problem Internet Overuse Behaviors in College Students: Readiness-to-Change and Receptivity to Treatment. $J$ Evid Inf Soc Work . [Crossref]

3. King DL, et al (2013) toward a consensus definition of pathological video-gaming: A systematic review of psychometric assessment tools. Clinical Psychology Review 33: 331-342.

4. Király $\mathrm{O}$, et al. Assessment of Problematic Internet Use and Online Video Gaming, in Mental Health in the Digital Age: Grave Dangers, Great Promise, V. Starcevic and E. Aboujaoude, Editors. 201, Oxford University Press: Oxford. p. 46-68.

5. Pontes HM, Griffiths MD (2014) Assessment of Internet Gaming Disorder in clinical research: Past and present perspectives. Clinical Research and Regulatory Affairs 31: $35-48$.

6. Kuss DJ (2013) Internet gaming addiction: current perspectives. Psychol Res Behav Manag 6: 125-137. [Crossref]

7. Griffiths, M.D., D.L. King, and Z. Demetrovics, DSM-5 internet gaming disorder needs a unified approach to assessment. Neuropsychiatry, 2014. 4(1): p. 1-4.

8. Petry NM, O'Brien CP (2013) Internet gaming disorder and the DSM-5. Addiction 108: 1186-1187. [Crossref]

9. Pearcy BTD, Roberts LD, McEvoy PM (2016) Psychometric Testing of the Personal
Internet Gaming Disorder Evaluation-9: A New Measure Designed to Assess Internet Gaming Disorder. Cyberpsychology, Behavior, and Social Networking.

10. Pontes HM, Király O, Demetrovics Z, Griffiths MD (2014) The conceptualisation and measurement of DSM-5 Internet Gaming Disorder: the development of the IGD-20 Test. PLoS One 9: e110137. [Crossref]

11. Fuster H, et al. (2015) Spanish validation of the Internet Gaming Disorder-20 (IGD-20) Test. Computers in Human Behaviour 56: 215-224.

12. Pontes HM, Griffiths MD (2015) Measuring DSM-5 Internet Gaming Disorder: Development and validation of a short psychometric scale. Computers in Human Behaviour 45: 137-143.

13. Pontes HM, Griffiths MD (2016) Portuguese Validation of the Internet Gaming Disorder Scale-Short-Form. Cyberpsychol Behav Soc Netw 19: 288-293. [Crossref]

14. Pontes HM, M Macur, MD Griffiths (2016) Construct validity and preliminary psychometric properties of the Internet Gaming Disorder Scale - Short-Form (IGDS9SF) among Slovenian youth: A nationally representative study. Journal of Behavioral Addictions 5(s1): 35 .

15. Lemmens JS, Valkenburg PM, Gentile DA (2015) The Internet Gaming Disorder Scale. Psychol Assess 27: 567-582. [Crossref]

16. Király O, Sleczka P, Pontes HM, Urbán R, Griffiths MD, et al. (2015) Validation of the Ten-Item Internet Gaming Disorder Test (IGDT-10) and evaluation of the nine DSM- 5 Internet Gaming Disorder criteria. Addict Behav. [Crossref]

17. van Rooij AJ, Schoenmakers TM, van de Mheen D (2015) Clinical validation of the C-VAT 2.0 assessment tool for gaming disorder: A sensitivity analysis of the proposed DSM-5 criteria and the clinical characteristics of young patients with 'video game addiction'. Addict Behav.

Copyright: (C2016 Pontes HM. This is an open-access article distributed under the terms of the Creative Commons Attribution License, which permits unrestricted use, distribution, and reproduction in any medium, provided the original author and source are credited. 